\title{
Kinetics of the Photocatalytic Decomposition of Bisphenol A on Modified Photocatalysts
}

\author{
Piotr Zawadzki ${ }^{*}$, Edyta Kudlek ${ }^{1}$ Mariusz Dudziak ${ }^{2}$ \\ 1 Silesian University of Technology, Faculty of Energy and Environmental Engineering, Institute of Water and \\ Wastewater Engineering, Konarskiego 22B, 44-100 Gliwice, Poland \\ 2 Silesian University of Technology, Faculty of Energy and Environmental Engineering, Institute of Water and \\ Wastewater Engineering, Division of Water Supply and Sewage Systems, Konarskiego 18, 44-100 Gliwice, \\ Poland \\ * Corresponding author's e-mail: zawadzki.piotr@onet.eu
}

\begin{abstract}
This paper presents the evaluation of the photocatalytic kinetics of bisphenol A decomposition in the presence of commercial titanium(IV) oxide and modified photocatalysts (composites). The following modification methods were used: mechanical mixing, calcination and impregnation. The decomposition process was carried out with the addition of photocatalysts and activated carbon at doses of $100 \mathrm{mg} / \mathrm{dm}^{3}$ and $25 \mathrm{mg} / \mathrm{dm}^{3}$, respectively. The photocatalytic process was performed in a reactor from the Heraeus Company (Warsaw, Poland) with a volume of $0.7 \mathrm{dm}^{3}$. The reactor was equipped with an immersed medium-pressure mercury lamp with a power of $150 \mathrm{~W}(\lambda=200-580 \mathrm{~nm})$. The degree of bisphenol A decomposition was determined by chromatographic analysis preceded by solid-phase extraction SPE. The qualitative-quantitative analysis was performed using a high-performance liquid chromatograph HPLC (UV detector, $\lambda=218 \mathrm{~nm}$ ) from Varian (Warsaw, Poland). The dependence of the BPA decomposition on the duration of irradiation was found, wherein the modified photocatalysts were the most effective (from 75 to $90 \%$ after 15 minutes). The order of photocatalyst efficiency has been proposed as follows: $\mathrm{TiO}_{2}<\mathrm{TiO}_{2} / \mathrm{AC}^{2}<\mathrm{C}_{\text {dextran }}-\mathrm{TiO}_{2} / \mathrm{AC}<$ $\mathrm{C}_{\text {methanol }}-\mathrm{TiO}_{2} / \mathrm{AC}<\mathrm{C}_{\text {ethanol }}-\mathrm{TiO}_{2} / \mathrm{AC}<\mathrm{TiO}_{2}-\mathrm{AC}$. The highest degree of decomposition was observed in the presence of $\mathrm{TiO}_{2} / \mathrm{AC}(99 \%)$. Numerous studies suggest that the results of the $\mathrm{TiO}_{2}$ photocatalytic oxidation of organic substances fit well with the Langmuir-Hinshelwood $(\mathrm{L}-\mathrm{H})$ kinetic model. The kinetic parameters of the photocatalysis process were carried out according to the L-H model. According to the pseudo-first-order parameters, the results showed that the decomposition of bisphenol A was most intensive in the first 15 minutes of the process.
\end{abstract}

Keywords: kinetics, photocatalysis, modified photocatalysts, bisphenol A

\section{INTRODUCTION}

The 2,2-Bis(4-hydroxyphenyl)propane, widely known as bisphenol A (BPA), is a pollutant classified as a contaminant of emerging concern (CEC). $\mathrm{BPA}$ is an organic compound used to produce polymers such as epoxy resins. It commonly appears in various everyday products, particularly in products that are in contact with food (infant feeding bottles, microwave ovenware, coatings on metal lids, etc.). BPA is considered an endocrine-disrupting compound (EDC) and can cause adverse endocrine disruptive effects. In the literature, bisphenol A is described as generating toxic effects in living organisms after short exposure times and chronic effects with long-term exposure. The described xenoestrogen is an anthropogenic impurity with a low acute toxicity, and poisoning from BPA is very rare [Careghini et al. 2015].

Bisphenol A is emitted into the environment mainly via untreated industrial wastewater during manufacturing processes, and it leaches from products stored in poorly maintained landfills. Therefore, many sources result in a continuous release of this compound and an increase in its concentration in aquatic ecosystems. Analysis of samples collected from surface water from all over the world has shown the presence of BPA in aquatic 
ecosystems in Portugal, Italy, Denmark, USA and China (Table 1). In the ranking of the five largest manufacturers of BPA, China is the largest manufacturer, and Asian countries account for a major share of the global production of BPA (approximately 2.4 million tons). Environmental studies in China have shown that the concentrations of BPA detected in surface waters were comparable to global levels (less than $1 \mu \mathrm{g} / \mathrm{dm}^{3}$ ) except for several areas with median concentrations higher than $4 \mu \mathrm{g} / \mathrm{dm}^{3}$ [Ma et al. 2006; Dong et al. 2009].

The presence of organic compounds in surface waters and the necessity of their removal is one of the most important aspects of water treatment technology. Considering the low susceptibility of micro-impurities to biological degradation and the difficulty of removal them with conventional water treatment and wastewater treatment systems, new methods should be sought to eliminate pollutants from aquatic ecosystems. An alternative to classical technologies are advanced oxidation processes (AOPs). Their common chemical feature is the formation of a hydroxyl radical $\left(\mathrm{OH}^{*}\right)$, which drives the oxidation processes of organic compounds. AOPs include methods such as ozonation, photolysis and photocatalysis. These processes do not transfer the substances to another phase (e.g., an activated sludge) that requires further processing and elimination but they enable the complete removal of pollutants from water [Pirila 2015]. Numerous studies have shown that AOPs are highly effective in the elimination of pharmaceutical substances [Bohdziewicz et al. 2013], endocrine-active compounds [Dudziak et al. 2014] and heavy metals [Lenoble et al. 2003].

In recent years, photocatalytic oxidation using titanium(IV) oxide $\left(\mathrm{TiO}_{2}\right)$ powder or other semiconductors has received considerable attention. The photoactivation of $\mathrm{TiO}_{2}$ requires enough energy to activate the semiconductor. A major drawback of commercial photocatalysts is their low activity un-

Table 1. Medium level of bisphenol A in the surface waters of the world

\begin{tabular}{|c|c|c|}
\hline Country & Level, $\mu \mathrm{g} / \mathrm{dm}^{3}$ & References \\
\hline Portugal & $70.00 \div 4000.00$ & $\begin{array}{c}\text { [Avzedo et al. } \\
\text { 2001] }\end{array}$ \\
\hline Netherlands & $<900.00 \div$ & $\begin{array}{c}\text { [Vethaak et al. } \\
2005]\end{array}$ \\
\hline China & 1000.00 & [Fu et al. 2007] \\
\hline USA & $<100.00 \div 800.00$ & $\begin{array}{c}\text { [Staples et al. } \\
2000]\end{array}$ \\
\hline Poland & $<2.88$ & $\begin{array}{c}\text { Kotowska et al. } \\
2014]\end{array}$ \\
\hline
\end{tabular}

der visible light (Vis). It forces the use of expensive, artificial light sources such as ultraviolet radiation (UV). Currently, second-generation visible-lightactive photocatalysts that can absorb the radiation in the visible range $(\lambda>400 \mathrm{~nm})$ are under investigation. Therefore, many works have been focused on the modification of titanium(IV) oxide nanoparticles. The modification of $\mathrm{TiO}_{2}$ has been used for various purposes, including increasing both the photocatalytic activity of the semiconductor and its efficiency in adsorbing pollutants, enhancing the separation performance of the $\mathrm{TiO}_{2}$ powder from the aqueous phase after process and neutralizing the intermediates oxidation products [Inagaki et al. 2005].

The aim of this work was to evaluate the photocatalytic kinetics of bisphenol A decomposition in the presence of commercial titanium(IV) oxide and modified photocatalysts (composites) based on $\mathrm{TiO}_{2}$, activated carbon and elemental carbon.

\section{MATERIALS AND METHODS}

In this experiment the experimental solutions were prepared using deionized water and an analytical standard of bisphenol A obtained from Sigma-Aldrich (Poznan, Poland) with a purity of $99.0 \%$. A constant concentration of xenobiotics equal to $1.0 \mathrm{mg} / \mathrm{dm}^{3}$ was used. The $\mathrm{pH}$ of the model solution was adjusted to 7 using $0,1 \mathrm{~mol} / \mathrm{dm}^{3} \mathrm{HCl}$ and $0.2 \mathrm{~mol} / \mathrm{dm}^{3} \mathrm{NaOH}$. The physicochemical characteristics of BPA are presented in Table 2.

The commercial $\mathrm{TiO}_{2}-\mathrm{P} 25$ (approximately $75 \%$ of anatase) with a specific surface area $\mathrm{S}_{\mathrm{BET}}$ of $50 \pm 15 \mathrm{~m}^{2} / \mathrm{g}$ and mean particle size of $21 \mathrm{~nm}$ was doped with carbonaceous materials. The sources of carbon were commercial activated carbon CWZ-30 from Gryfskand, methyl alcohol of a purity of $99.5 \%$ and ethyl alcohol of a purity of 96.0\% from Avantor Performance Materials Poland S.A. (Gliwice, Poland) and dextran 110000 with $98.5 \%$ purity by Polfa KUTNO (Kutno, Poland). The physicochemical characteristics of the base materials are summarized in Table 3 .

\section{SYNTHESIS OF PHOTOCATALYST SAMPLES}

Six types of photocatalysts were tested, namely a commercial titanium(IV) oxide, $\mathrm{TiO}_{2}$-activated carbon mixture $\left(\mathrm{TiO}_{2}-\mathrm{AC}\right)$, com- 
Table 2. Physicochemical characteristics of bisphenol A

\begin{tabular}{|c|c|c|}
\hline Chemical structure & \multicolumn{2}{|c|}{ Physicochemical properties } \\
\hline \multirow{9}{*}{$\mathrm{HO}-\mathrm{CH}_{3}$} & Molecular formula & $\mathrm{C}_{15} \mathrm{H}_{16} \mathrm{O}_{2}$ \\
\hline & Molecular weight $[\mathrm{g} / \mathrm{mol}]$ & 228.28 \\
\hline & Water solubility $\left(25^{\circ} \mathrm{C}\right)$ & Insoluble $\left(200-300 \mathrm{mg} / \mathrm{dm}^{3}\right)$ \\
\hline & Vapor pressure $\left(20^{\circ} \mathrm{C}\right)[\mathrm{mmHg}]$ & $4.0 \times 10^{-8}$ \\
\hline & $\log \mathrm{K}_{\mathrm{ow}}$ & $2.20-3.82$ \\
\hline & $\log K_{o c}$ & $2.53-4.23$ \\
\hline & Dissociation constant in $25^{\circ} \mathrm{C}\left(\mathrm{pK}_{\mathrm{a}}\right)$ & 9.60 \\
\hline & Odor & Mild phenolic \\
\hline & Form & White flakes or crystals \\
\hline
\end{tabular}

Table 3. Physicochemical characteristics of $\mathrm{TiO}_{2}$ and activated carbon

\begin{tabular}{|l|l|l|}
\hline & Activated carbon & Photocatalyst \\
\hline Symbol, origin & $\begin{array}{l}\text { CWZ-30, } \\
\text { Gryfskand }\end{array}$ & $\begin{array}{l}\text { P-25, Evonik } \\
\text { Degussa GmbH }\end{array}$ \\
\hline $\begin{array}{l}\text { Surface area } \\
{\left[\mathrm{m}^{2} / \mathrm{g}\right]}\end{array}$ & 1134.0 & $35.0-65.0$ \\
\hline Particle size $[\mathrm{nm}]$ & - & 21.0 \\
\hline Granulation $[\%]$ & 90.0 & - \\
\hline Denisty $\left[\mathrm{g} / \mathrm{cm}^{3}\right]$ & $0.28-0.36$ & 4.26 \\
\hline
\end{tabular}

posite consisting of activated carbon and titanium dioxide $\left(\mathrm{TiO}_{2} / \mathrm{AC}\right)$ and composites consisting of activated carbon, titanium dioxide and three sources of elemental carbon (methanol $\left(\mathrm{C}_{\text {methanol }}-\mathrm{TiO}_{2} / \mathrm{AC}\right)$, ethanol $\left(\mathrm{C}_{\text {ethanol }}-\mathrm{TiO}_{2} / \mathrm{AC}\right)$ and dextran $\left.\left(\mathrm{C}_{\text {dextran }}-\mathrm{TiO}_{2} / \mathrm{AC}\right)\right)$. The photocatalysts doped with carbonaceous materials were prepared using a hybrid method based on the following preparation techniques: mechanical mixing, calcination and impregnation.

The modification of commercial $\mathrm{TiO}_{2}$ was started by mixing the semiconductor nanoparticles and activated carbon in deionized water with a ratio of 80:20 (w/w). The suspension was magnetically stirred at room temperature for 30 minutes in the dark and then calcined in a furnace at $300^{\circ} \mathrm{C}$ for 8 hours. The resulting photocatalyst is referred to as $\mathrm{TiO}_{2} / \mathrm{AC}$. To prepare the alcoholmodified photocatalysts, the same procedure was repeated; however, methanol or ethanol was added dropwise to the previously prepared composite $(1: 1, \mathrm{w} / \mathrm{v})$. The $\mathrm{C}-\mathrm{TiO}_{2} / \mathrm{AC}$ photocatalyst was magnetically stirred in the dark for $30 \mathrm{~min}$ utes and then placed in the drying oven at $80^{\circ} \mathrm{C}$ for 6 hours. The following symbols were used: $\mathrm{C}_{\text {methanol }}-\mathrm{TiO}_{2} / \mathrm{AC}$ and $\mathrm{C}_{\text {ethanol }}-\mathrm{TiO}_{2} / \mathrm{AC}$. The composite marked as $\mathrm{C}_{\text {dextran }}-\mathrm{TiO}_{2} / \mathrm{AC}$ was prepared by thoroughly dissolving sugar in a $\mathrm{TiO}_{2}$-AC suspension with a ratio of 80:20 (w/w). Details of each calcination process are shown in Table 4.

\section{INSTRUMENTS AND ANALYTICAL METHODS}

Deionized water spiked with analytical standards of the studied compounds at a constant concentration of $1000 \mathrm{mg} / \mathrm{dm}^{3}$ was irradiated with an immersed medium-pressure

Table 4. Characteristics of photocatalysts preparation methods

\begin{tabular}{|c|c|c|c|c|c|}
\hline \multirow{3}{*}{ Catalyst } & \multirow{3}{*}{ Carbon source } & \multicolumn{3}{|c|}{ Conditions/preparation } & \multirow{3}{*}{ Symbol } \\
\hline & & \multicolumn{2}{|c|}{ Calcination } & \multirow{2}{*}{ Preparation } & \\
\hline & & Temperature $\left[{ }^{\circ} \mathrm{C}\right]$ & Time [h] & & \\
\hline $\mathrm{TiO}_{2}-\mathrm{AC}$ & commercial AC & - & - & $\begin{array}{l}\text { mixing } \mathrm{TiO}_{2} \\
\text { with } \mathrm{AC}\end{array}$ & $\mathrm{TiO}_{2}-\mathrm{AC}$ \\
\hline $\mathrm{TiO}_{2} / \mathrm{AC}$ & commercial AC & 300 & 8 & $\begin{array}{c}\text { mixing } \mathrm{TiO}_{2} \\
\text { with } \mathrm{AC} \text {, calcination }\end{array}$ & $\mathrm{TiO}_{2} / \mathrm{AC}$ \\
\hline \multirow{2}{*}{$\mathrm{C}_{\text {methanol }} \mathrm{TiO}_{2} / \mathrm{AC}$} & \multirow{2}{*}{$\begin{array}{l}\text { commercial AC, } \\
\text { methanol }\end{array}$} & 300 & 8 & $\begin{array}{c}\text { mixing } \mathrm{TiO}_{2} \\
\text { with } \mathrm{AC} \text {, calcination }\end{array}$ & \multirow{2}{*}{$\mathrm{C}_{\text {methanol }}-\mathrm{TiO}_{2} / \mathrm{AC}$} \\
\hline & & 80 & 6 & $\begin{array}{l}\text { addition of methanol into } \\
\mathrm{TiO}_{2} / \mathrm{AC} \text {, drying }\end{array}$ & \\
\hline $\mathrm{C}_{\text {ethanol }} \mathrm{TiO}_{2} / \mathrm{AC}$ & $\begin{array}{c}\text { commercial AC, } \\
\text { ethanol }\end{array}$ & 300 & 8 & $\begin{array}{l}\text { addition of methanol into } \\
\mathrm{TiO}_{2}-\mathrm{AC} \text {, calcination }\end{array}$ & $\mathrm{C}_{\text {ethanol }}-\mathrm{TiO}_{2} / \mathrm{AC}$ \\
\hline $\mathrm{C}_{\text {dextran }} \mathrm{TiO}_{2} / \mathrm{AC}$ & $\begin{array}{c}\text { commercial } \mathrm{AC}, \\
\text { dextran }\end{array}$ & 300 & 8 & $\begin{array}{l}\text { dissolution of dextran } \\
\text { in } \mathrm{TiO}_{2}-\mathrm{AC} \text {, calcination }\end{array}$ & $\mathrm{C}_{\text {dextran }}-\mathrm{TiO}_{2} / \mathrm{AC}$ \\
\hline
\end{tabular}


$150 \mathrm{~W}$ mercury lamp. The lamp irradiation ranged from 300 to $580 \mathrm{~nm}$. The process of heterogenic photocatalysis was conducted in a laboratory batch reactor (volume of $700 \mathrm{~cm}^{3}$ ) by Heraeus (Figure $1)$. The temperature of the reaction mixture was approximately $20-21^{\circ} \mathrm{C}$ owing to a cooling jacket. An aeration pump with a capacity of $4 \mathrm{dm}^{3}$ air for 1 minute was introduced into the reactor.

The photocatalytic process was investigated in the presence of a commercial photocatalyst, activated carbon and modified photocatalysts. Photocatalytic experiment was carried out at a catalysts dose of $100 \mathrm{mg} / \mathrm{dm}^{3}$. In the assisted photocatalysis, the dose of activated carbon applied to the reaction mixture reached $25 \mathrm{mg} / \mathrm{dm}^{3}$. The solutions of bisphenol A were irradiated continuously for 45 minutes. In the preliminary study, a 15-minute contact time was set to ensure the adsorption of micropollutants on the surface of the catalyst (adsorption). The adsorption process was carried out in the dark. In this way, the sorption efficiency of the photocatalysts was determined. The samples for analysis were collected after 5 , $10,15,20,30$ and $45 \mathrm{~min}$ of the reaction. The heterogenic photocatalysis in the presence of pure titanium dioxide is denoted as $\mathrm{TiO}_{2}$, whereas the

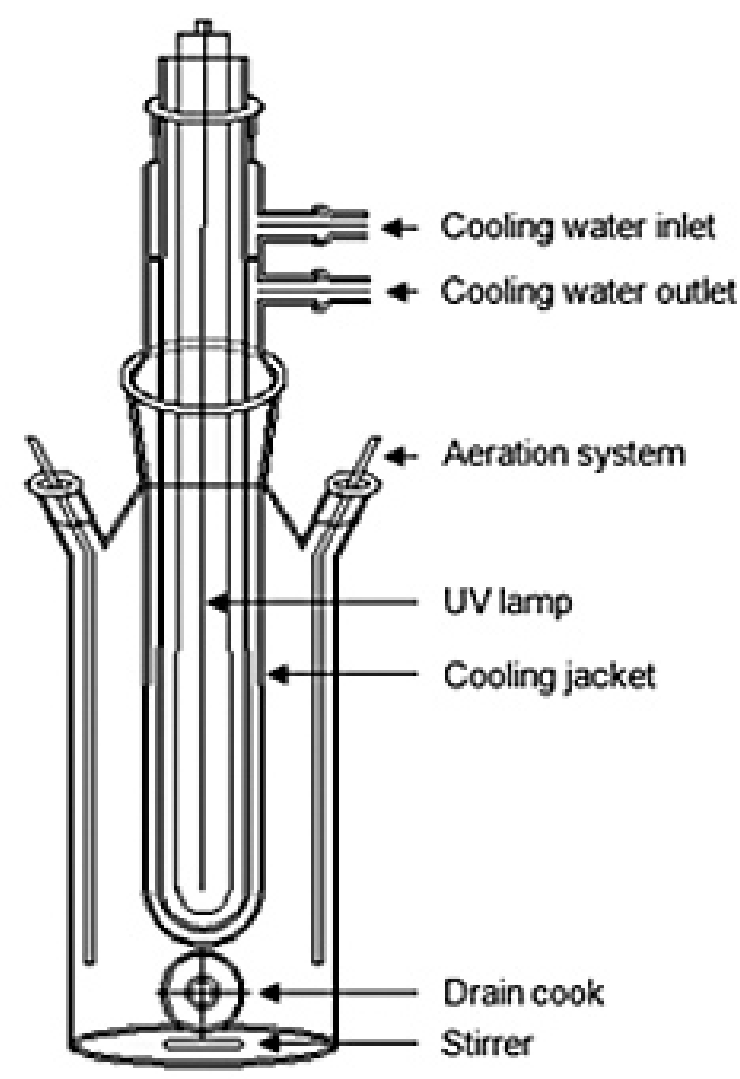

Figure 1. Scheme of the photocatalytic batch reactor [Kudlek et al. 2015] mixture of titanium(IV) oxide and activated carbon is labelled as $\mathrm{TiO}_{2}-\mathrm{AC}$. For the modified photocatalysts, the following determinations were used: $\mathrm{TiO}_{2} / \mathrm{AC}, \mathrm{C}_{\text {methanol }}-\mathrm{TiO}_{2} / \mathrm{AC}, \mathrm{C}_{\text {ethanol }}-\mathrm{TiO}_{2} / \mathrm{AC}$ and $\mathrm{C}_{\text {dextran }}-\mathrm{TiO}_{2} / \mathrm{AC}$.

The removal rates of bisphenol A before and after the photocatalytic process were determined by the chromatographic analysis preceded by solid-phase extraction (SPE). The activated carbon and catalyst particles were separated from the treated solution using a $0.45 \mu \mathrm{m}$ glass filter filtration kit (Merck Millipore Company, Poznan, Poland) connected to vacuum pump by AGA Labor (Warsaw, Poland). The samples were extracted with solid-phase extraction in single-use C-18 Supelclean ${ }^{\text {TM }}$ ENVI-18 columns with a volume of $6 \mathrm{~cm}^{3}$ and $1.0 \mathrm{~g}$ of the solid phase. The bed was conditioned with $5 \mathrm{~cm}^{3}$ of acetonitrile and $5 \mathrm{~cm}^{3}$ of methanol and washed with $5 \mathrm{~cm}^{3}$ of water to remove any residue. The analyte was eluted from the column with a $3 \mathrm{~cm}^{3}$ mixture of acetonitrile and methanol $(60: 40, \mathrm{v} / \mathrm{v})$. The qualitative-quantitative analysis was performed using a high-performance liquid chromatograph HPLC (UV detector, $\lambda=218 \mathrm{~nm}$ ) equipped with a Hypersil GOLD column by Thermo Scientific (length $-25 \mathrm{~cm}$, diameter $-4.6 \mathrm{~mm}$ and granulation -5.0 $\mu \mathrm{m})$ with methanol as the mobile phase.

Numerous studies of $\mathrm{TiO}_{2}$ photocatalytic oxidation of organic pollutants have shown that the corresponding data fit the Langmuir-Hinshelwood $(\mathrm{L}-\mathrm{H})$ kinetic model. Therefore, for very low concentrations of micropollutants in aquatic environment, e.g., bisphenol A, the L-H equilibrium simplifies to a pseudo-first-order kinetic model [Asenjo et al. 2003; Kumar et al. 2008]. The Langmuir-Hinshelwood kinetic model (Equation 1) is assumed as follows:

$$
r=-\frac{d C}{d t}=\frac{k \cdot K \cdot C}{1+K \cdot C}
$$

The pseudo-first order rate constant $k$ was determined for each photocatalyst since it enables one to estimate the photocatalytic activity of the catalyst. The integral form of the pseudo-first-order rate equation is usually expressed by Equation 2:

$$
\ln \frac{C_{0}}{C}=k t
$$

where $C_{0}$ and $C$ are the initial and final concentrations of BPA at time,

$t=0$ and $t=t$, where $t$ is the irradiation time. 


\section{RESULTS AND DISCUSSION}

The adsorption behaviour and the pollutant decomposition efficiency increase as the surface area of the photocatalyst increases. Ao et al. [Ao et al. 2003] observed that a higher active surface area provides more hydroxyl radicals and, by extension, a higher degree of decomposition of pollutants. The elimination of bisphenol A was the most effective during the sorption process of contaminants on the photocatalyst nanoparticles, which is evidenced by the results from " 0 " min, i.e., before the radiation source was switched on (Figure 2). It was observed that the compound was adsorbed in the range from 50 to $97 \%$. The highest value of this parameter was observed in the system referred to as $\mathrm{TiO}_{2}$-AC. A highly developed surface area of activated carbon in the range from 700 to $1800 \mathrm{~m}^{2} / \mathrm{g}$ plays a crucial role in the sorption of bisphenol A. However, in this case the decomposition of the studied compound was dominated by the adsorption process, and the particles of the macromolecular substance were only transferred to another phase. While the chromatographic analysis showed
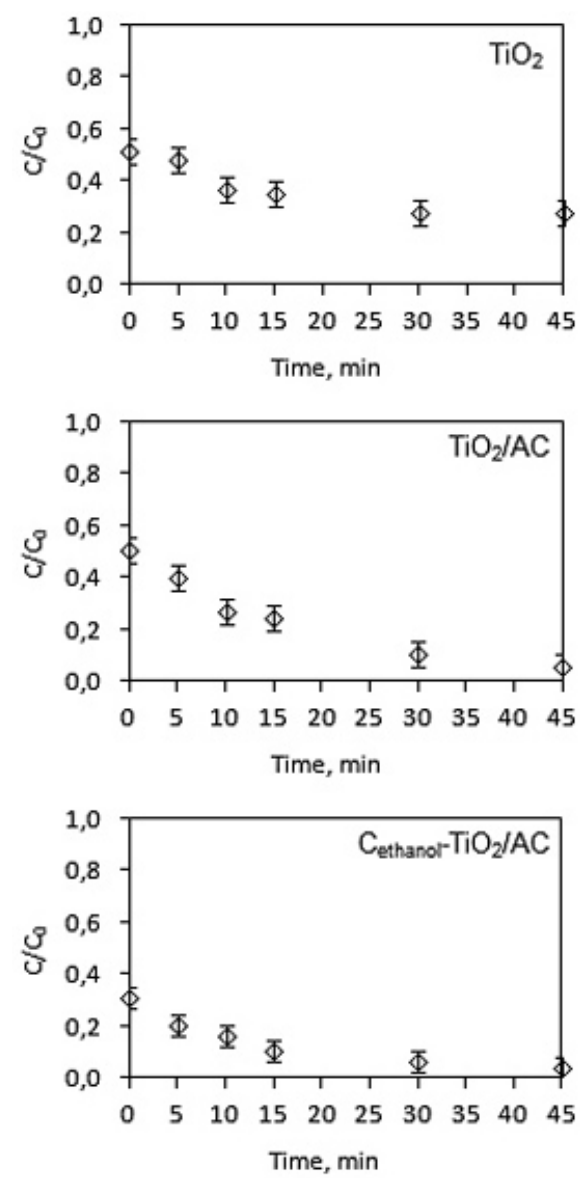

a reduction in the concentration of bisphenol A, it could be adsorbed deeply inside the micro and mesopores of the activated carbon (Figure 3). Thus, it was not decomposed. Despite the important role of the surface area of photocatalysts, Matsunaga et al. [Matsunaga and Inagaki 2006] showed a negative effect of carbon on the activity of the photocatalysts. Large amounts of carbon coating the surface of $\mathrm{TiO}_{2}$ reduced its ability to absorb UV light.

Based on the chromatographic analysis results, the decomposition of bisphenol A was higher for modified photocatalysts than for commercial $\mathrm{TiO}_{2}$. Additionally, the increased time of exposure to UV radiation showed a decrease in the BPA levels. The results are presented in Figure 2 in consideration of the catalyst used. The greatest reduction in the concentration of bisphenol A was observed for the experimental solutions irradiated in the presence of the considered materials. The initial concentration of the tested micropollutant was reduced by 65 to $98 \%$ over 15 minutes of irradiation. After 45 minutes of irradiation, the highest degree of decomposition of the organic compound was found in the $\mathrm{TiO}_{2}-\mathrm{AC}$
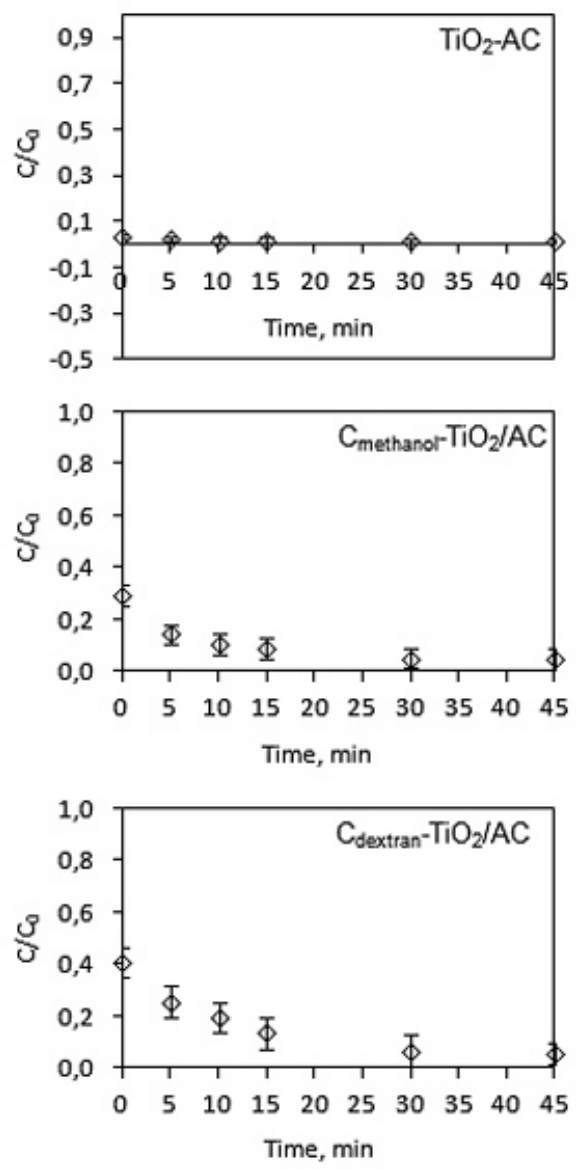

Figure 2. Decomposition of bisphenol A in the photocatalytic process at different photocatalyst configurations 

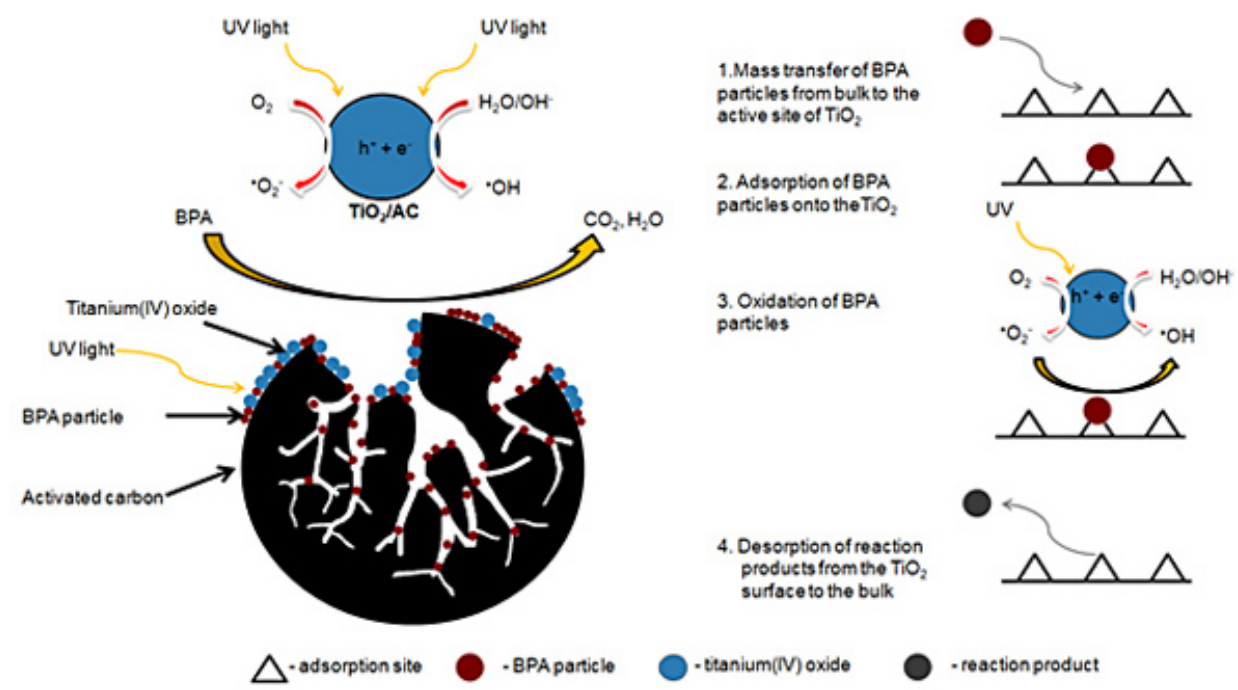

Figure 3. Proposed mechanism of adsorption and decomposition of bisphenol A on modified photocatalysts. Based on [Xing et al. 2016; Singh et al. 2016]

process (99\%). The photocatalysts doped with elemental carbon were equally as effective. For the elemental carbon-doped photocatalysts, the initial concentration of bisphenol A was reduced by approximately $95 \%$.

The effect of the number of elemental carbon atoms on the efficiency of bisphenol A decomposition was observed for the following configurations: $\mathrm{C}_{\text {methanol }}-\mathrm{TiO}_{2} / \mathrm{AC}, \mathrm{C}_{\text {ethanol }}-\mathrm{TiO}_{2} / \mathrm{AC}$ and $\mathrm{C}_{\text {dextran }}-\mathrm{TiO}_{2} / \mathrm{AC}$. The concentration ratio $\mathrm{C} / \mathrm{C}_{0}$ increased as the number of carbon atoms increased. After irradiation of experimental solution in the presence of the methanol-modified catalyst (one carbon atom), the decomposition level of bisphenol A was greater compared to that of the $\mathrm{C}_{\text {dextran }}-\mathrm{TiO}_{2} / \mathrm{AC}$ photocatalyst, which was modified using a compound of six carbon atoms.

Based on the Langmuir-Hinshelwood model, the following kinetic parameters of the photocatalysis process were carried out: pseudo-firstorder rate constant $k$, the coefficient of determination $R^{2}$ and the half-life $t_{1 / 2}$. The results are described in Table 5. The dependence of the $\ln \left(\mathrm{C} / \mathrm{C}_{0}\right)$ function on the time of irradiation $\left(t_{1 / 2}\right)$ is shown in Figure 4.

From earlier observations, the pseudo-firstorder parameters indicated that the bisphenol A oxidation reaction was much faster in the presence of modified photocatalysts. One of the parameters indicating the dynamics of the ongoing processes is the pseudo-first-order rate constant $k$. Analysis of the $k$ parameter in the photocatalytic process indicates rapid decomposition during first minutes of the photocatalytic processes. The re- sults showed that the decomposition of bisphenol A was most intense in the first 15 minutes of irradiation. Within this time, the data fitted to the linear equation showed very good correlation coefficients $R^{2}$. However, lowering the $k$ constant from 15 to 30 minutes of the photooxidation process may be due to the reduction of the photocatalyst surface due to the agglomeration of the intermediate particles. The two-stage oxidation process is mainly attributed to the formation of intermediate products, which, after adsorbing on the photocatalyst surface, block the active sites of the semiconductor. Their quantity depends on the amount of output pollutants adsorbed on the photocatalyst surface and, thus, on the success of the pollutant decomposition [Ao et al. 2003]. In elemental carbon-doped photocatalysts, the correlation between the degree and rate of recombination of the electron-hole pairs $\left(\mathrm{e}^{-}-\mathrm{h}^{+}\right)$and the number of elemental carbon atoms in the structure of pure $\mathrm{TiO}_{2}$ has been observed. When the concentration of foreign elements is too high, it causes the distance between the $\mathrm{e}^{-}-\mathrm{h}^{+}$pair to be too low. The effect is a lack of the separating force [Carp et al. 2004]. Photocatalysts doped with elemental carbon exhibit a pseudo-first-order rate constant, $k$, that is more than three times higher than that of commercial titanium(IV) oxide. The greatest value of the $k$ parameter was noted in the catalyst referred to as $\mathrm{C}_{\text {methanol }}-\mathrm{TiO}_{2} / \mathrm{AC}$ $\left(k=0,078 \mathrm{~min}^{-1}\right)$. No intermediate bisphenol A degradation was found for only the $\mathrm{TiO}_{2} / \mathrm{AC}$ composite. This phenomenon could be explained by the inhibition of the electron-hole pair recom- 

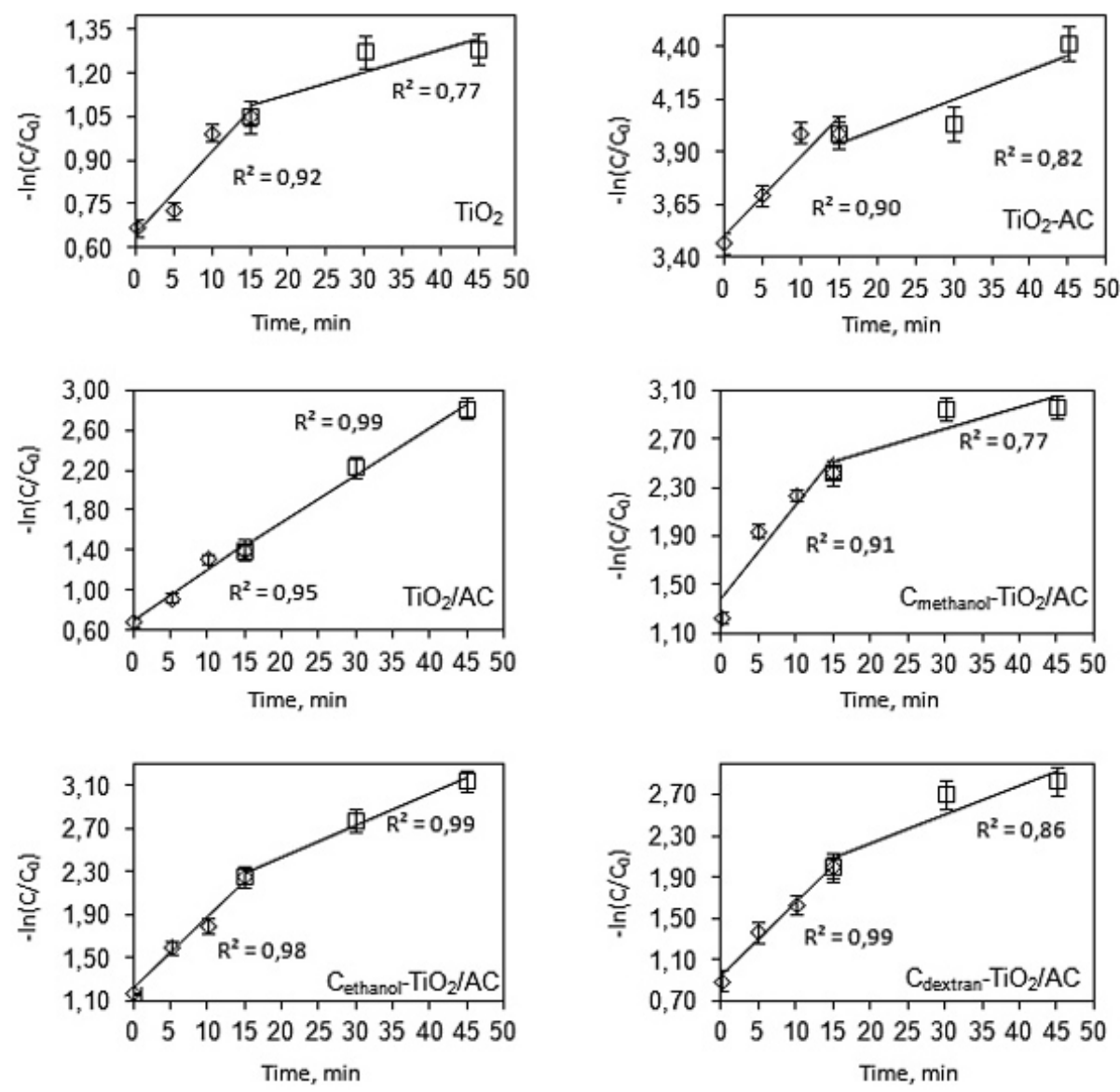

Figure 4. Kinetics of the bisphenol A decomposition in the photocatalytic process with different photocatalyst configurations.

bination process, which in turn leads to the inhibition of the pollutant decomposition.

Above observations are confirmed by the analysis of the half-life $t_{1 / 2}$ results, which are presented in Table 5. Statistical indices, such as the standard deviations (SD), were used to evaluate the model adequacy. It is defined in Equation 3:

$$
S D=\sqrt{\frac{\sum\left(X_{i}-X\right)^{2}}{N-1}}
$$

where: $X_{i}$ is the experimental values of parameters,
$X$ is the mean value of the parameter,

$N$ is the number of experimental data.

Data analysis indicates satisfactory accuracy in the estimation of the kinetic constant for the measured parameters (pseudo-first-order rate constant $k$, coefficient of determination $R^{2}$, and half-life $t_{1 / 2}$ ). During the first period of the process (up to 15 minutes), the appointed half-life of the model was higher compared to the decomposition of bisphenol A from 15 to 45 minutes of photocatalysis. This was due to the increasing level of intermediate compounds with the elongation of

Table 5. Pseudo first-order parameters during photocatalysis process

\begin{tabular}{|c|c|c|c|c|c|c|}
\hline \multirow{2}{*}{ Catalyst } & \multicolumn{5}{|c|}{ Pseudo first-order parameters } \\
\cline { 2 - 7 } & \multicolumn{2}{|c|}{$\mathrm{k}, \mathrm{min}^{-1}$} & \multicolumn{2}{c|}{$\mathrm{R}^{2},-$} & \multicolumn{2}{c|}{$\mathrm{t} / 2, \mathrm{~min}$} \\
\cline { 2 - 7 } & $0-15$ & $15-30$ & $0-15$ & $15-30$ & $0-15$ & $15-30$ \\
\hline $\mathrm{TiO}_{2}$ & $0.028 \pm 0.006$ & $0.007 \pm 0.002$ & $0.92 \pm 0.03$ & $0.77 \pm 0.03$ & $47.9 \pm 9.27$ & $237.7 \pm 38.95$ \\
\hline $\mathrm{TiO}_{2}-\mathrm{AC}$ & $0.037 \pm 0.006$ & $0.014 \pm 0.002$ & $0.90 \pm 0.01$ & $0.82 \pm 0.05$ & $113.5 \pm 17.77$ & $315.4 \pm 42.26$ \\
\hline $\mathrm{TiO}_{2} / \mathrm{AC}$ & $0.051 \pm 0.008$ & $0.047 \pm 0.005$ & $0.95 \pm 0.03$ & $0.99 \pm 0.01$ & $27.3 \pm 2.10$ & $30.3 \pm 2.49$ \\
\hline $\mathrm{C}_{\text {methanol }}-\mathrm{TiO}_{2} / \mathrm{AC}$ & $0.078 \pm 0.005$ & $0.017 \pm 0.004$ & $0.91 \pm 0.03$ & $0.77 \pm 0.01$ & $26.5+0.25$ & $172.5 \pm 34.48$ \\
\hline $\mathrm{C}_{\text {ethanol }}-\mathrm{TiO}_{2} / \mathrm{AC}$ & $0.069 \pm 0.005$ & $0.029 \pm 0.005$ & $0.96 \pm 0.03$ & $0.98 \pm 0.01$ & $27.2 \pm 2.13$ & $87.2 \pm 8.18$ \\
\hline $\mathrm{C}_{\text {dextran }}-\mathrm{TiO}_{2} / \mathrm{AC}$ & $0.071 \pm 0.001$ & $0.027 \pm 0.002$ & $0.99 \pm 0.01$ & $0.86 \pm 0.01$ & $22.9 \pm 0.81$ & $87.9 \pm 3.03$ \\
\hline
\end{tabular}


Table 6. Classification of reaction rates based on half-lives [Wright 2004]

\begin{tabular}{|c|c|c|}
\hline Half-life, $\mathrm{s}$ & Time span for near-completion & Rate classification \\
\hline $10^{-15}-10^{-12}$ & ps or less & ultra fast rate \\
\hline $10^{-12}-10^{-6}$ & $\mu$ or less & very fast rate \\
\hline $10^{-6}-1$ & seconds & fast rate \\
\hline $1-10^{3}$ & minutes or hours & moderate rate \\
\hline $10^{6}-10^{3}$ & weeks & slow rate \\
\hline$>10^{6}$ & weeks or years & verw rate \\
\hline
\end{tabular}

the irradiation time. The half-life $t_{1 / 2}$ of bisphenol A was reduced from $48 \mathrm{~min}$ and $113 \mathrm{~min}$ for $\mathrm{TiO}_{2}$ and $\mathrm{TiO}_{2}-\mathrm{AC}$, respectively, to approx. 26 minutes for the modified photocatalysts. $\mathrm{TiO}_{2}$ doped with dextran had the shortest half-life of all the tested photocatalysts. Table 6 presents the classification of the chemical reaction rates based on their halflives. It was observed that in the first 15 minutes the bisphenol A photodegradation process proceeded at a moderate rate. Recombination of the electron-hole pairs slowed the reaction, whereby the continued irradiation of the solutions allowed the reaction to be classified as slow.

\section{CONCLUSIONS}

In this paper, the kinetics of bisphenol A decomposition in the presence of commercial titanium(IV) oxide and photocatalysts modified with carbonaceous materials were evaluated. It was found that the level of bisphenol A decomposition increases with irradiation time wherein the modified photocatalysts were the most effective compared to commercial $\mathrm{TiO}_{2}$. The proposed hybrid method involved the modification of titanium dioxide to produce materials with enhanced properties for removing BPA in comparison to the properties of commercial titanium dioxide. Therefore, the addition of carbon sources such as alcohols, sugars and activated carbon generated photocatalysts characterized by higher activity. It was observed that the photocatalysts adsorbed the tested compound in the range from 50 to $97 \%$. A significant effect of activated carbon on this process was found. Modification of the pure photocatalyst intensified the decomposition process of the organic compound, demonstrating a removal rate that exceeded $98 \%$. Based on the Langmuir-Hinshelwood model, a significant difference between the rate of micropollutant degradation in the first 15 minutes of irradiation and between 15 and 45 minutes of the process was found. Half-lives of the compound in the first 15 minutes of the process ranged from 22 to 27 minutes. The $t_{1 / 2}$ value was half that of commercial titanium(IV) oxide. The analysis of the photochemical oxidation kinetics revealed the two-stage oxidation process of the bisphenol A decomposition. No intermediate bisphenol A degradation was found only for the $\mathrm{TiO}_{2} /$ $\mathrm{AC}$ composite, indicating a slowdown in the recombination process of the electron-hole pairs, which contributes to the inhibition of the pollutant decomposition reaction.

\section{REFERENCES}

1. Ao C.H., Lee S.C., Yu J.C. 2003. Photocatalyst TiO2 supported on glass fiber for indoor air purification: effect of $\mathrm{NO}$ on the photodegradation of $\mathrm{CO}$ and NO2. J. Photochem. Photobiol. Chem. 156(1-3), 171-177.

2. Asenjo N.G., Santamaria R., Blanco C., Granda M., Alvarez P., Menendez R. 2013. Correct use of the Langmuir-Hinshelwood equation for proving the absence of a synergy effect in the photocatalytic degradation of phenol on a suspended mixture of titania and activated carbon. Carbon. 55, 62-69.

3. Azevedo D.A., Lacorte S., Viana P., Barcelo D. 2001. Occurrence of nonylphenol and bisphenol A in surface waters from Portugal. J. Brazil Chem. Soc. 12(4), 532-537.

4. Bohdziewicz J., Kudlek-Jelonek E., Dudziak M. 2013. Analytical control of diclofenac removal in the photocatalytic oxidation process. Arch. Civil Engin. Environ. 6(3), 71-75.

5. Careghini A., Mastorgio A. F., Saponaro S., Sezenna E. 2015. Bisphenol A, nonylphenols, benzophenones, and benzotriazoles in soils, groundwater, surface water, sediments, and food: a review. Environ. Sci. Pollut. Res. 22(8):5711-5741.

6. Carp O., Huisman C.L., Reller A. 2004. Photoinduced reactivity of titanium dioxide, Prog. Solid State Chem. 32(1-2), 33-177. 
7. Dong J., Li X L., Liang R. J. 2009. BisphenolApollution of surface water and its environmental factors. J. Ecol. Rural. Environ. 25(2), 94-97.

8. Dudziak M., Burdzik-Niemiec E. 2014. Comparative studies on elimination of estrogens and xenoestrogens by the oxidation processes. Ecol. Chem. Eng. A. 21(2), 189-198.

9. Fu M., Li Z., Gao H. 2007. Distribution characteristics of nonylphenol in Jiaozhou Bay of Qingdao and its adjacent rivers. Chemosphere. 69(7), 1009-1016.

10. Inagaki M., Kojin F., Tryba B., Toyoda M. 2005. Carbon-coated anatase: the role of the carbon layer for photocatalytic performance. Carbon. 43(8), 1652-1659.

11. Kudlek E., Bohdziewicz J., Dudziak M. 2015. Elimination of pharmaceutical compounds from municipal wastewater by photocatalysis, microfiltration and nanofiltration. Acta Innov. 16, 12-19.

12. Kumar K.V., Porkodi K., Rocha F. 2008. Langmuir-Hinshelwood kinetics - A theoretical study. Catal. Comm. 9(1), 82-84.

13. Lenoble V., Deluchat B., Serpaud J., Bollinger J. 2003. Arsenite oxidation and arsenate determination by the molybdene blue method. Talanta. 61(3), 267-276.
14. Ma X.Y., Gao N.Y., Li Q.S., Xu B., Le L.S., Wu J.M. 2006. Investigation of several endocrine disrupting chemicals in Huangpu River and water treatment units of a waterworks. China Water and Wastewater. 22(1-4), 10-16.

15. Matsunaga T., Inagaki M. 2006. Carbon-coated anatase for oxidation of methylene blue and NO. Appl. Cat. Environ. 64(1-2), 9-12.

16. Pirilä M. 2015. Adsorption and photocatalysis in water treatment: active, abundant and inexpensive materials and methods. Acta Universitatis Ouluensis, University Of Oulu, Oulu.

17. Staples C.A., Dorn P.B., Klecka G.M., O’block S.T., Branson D.R., Harris L.R. 2000. Bisphenol A concentrations in receiving waters near US manufacturing and processing facilities. Chemosphere. 40(5), 521-525.

18. Wright M.R. 2004. An introduction to chemical kinetics. John Wiley and Sons, England..

19. Vethaak A.D., Lahr J., Schrap S.M., Belfroid A.C., Rijs G.B.J., Gerritsen A., de Boer J., Bulder A.S., Grinwis G.C.M., Kuiper R.V., Legler J., Murk T.A.J., Peijnenburg W., Verhaar H.J.M., de Voogt P. 2005. An integrated assessment of estrogenic contamination and biological effects in the aquatic environment of The Netherlands. Chemosphere. 59(4), 511-524. 